\title{
The Assessment of Vitamin D Levels in Pregnant Women is not Associated to Fetal Growth Restriction: A Cross Sectional Study
}

\section{A avaliação dos níveis de vitamina $D$ em gestantes não está associada à restrição do crescimento fetal: um estudo transversal}

\author{
Vivian Macedo Gomes Marçal ${ }^{10}$ Francisco Lázaro Pereira Sousa ${ }^{2(1)}$ Silvia Daher ${ }^{10}$ \\ Raquel Margiotte Grohmann ${ }^{10}$ Alberto Borges Peixoto ${ }^{3,4(0)}$ Edward Araujo Júnior ${ }^{10}$ \\ Luciano Marcondes Machado Nardozza ${ }^{1}$ ()
}

\footnotetext{
${ }^{1}$ Department of Obstetrics, Escola Paulista de Medicina, Universidade Federal de São Paulo, São Paulo, SP, Brazil

2 Department of Obstetrics and Gynecology, Faculdade de Ciências Médicas de Santos, Santos, SP, Brazil

${ }^{3}$ Department of Gynecology and Obstetrics, Universidade Federal do

Triângulo Mineiro, Uberaba, MG, Brazil

${ }^{4}$ Gynecology and Obstetrics Service, Hospital Universitário Mário

Palmério, Universidade de Uberaba, Uberaba, MG, Brazil
}

Address for correspondence Edward Araujo Júnior, PhD, R. Botucatu, 740, 04023-062, Vila Clementino, São Paulo, SP, Brazil (e-mail: araujojred@terra.com.br).

Rev Bras Ginecol Obstet 2021;43(10):743-748.

\author{
Abstract \\ Keywords \\ - pregnancy \\ - maternal serum levels \\ - vitamin D \\ - small for gestational \\ age \\ - fetal growth \\ restriction
}

Objective To assess maternal serum levels of vitamin $D$ in fetuses appropriate for gestational age (AGA), small for gestational age (SGA), and with fetal growth restriction (FGR) according to estimated fetal weight (EFW).

Methods This cross-sectional study included 87 pregnant women between 26 and 36 weeks of gestation: 38 in the AGA group, 24 in the SGA group, and 25 in the FGR group. Maternal serum vitamin $D$ levels were assessed using the chemiluminescence method. The Fisher exact test was used to compare the results between the groups. Results The mean \pm standard deviation (SD) of maternal age (years) and body mass index $\left(\mathrm{kg} / \mathrm{m}^{2}\right)$ in the AGA, SGA, and FGR groups were $25.26 \pm 8.40 / 26.57 \pm 4.37$; $25.04 \pm 8.44$ / 26.09 \pm 3.94 ; and $25.48 \pm 7.52$ / $26.24 \pm 4.66$, respectively $(p>0.05)$. The maternal serum vitamin D levels (mean \pm SD) of the AGA, SGA, and FGR groups were $22.47 \pm 8.35 \mathrm{ng} / \mathrm{mL}, 24.80 \pm 10.76 \mathrm{ng} / \mathrm{mL}$, and $23.61 \pm 9.98 \mathrm{ng} / \mathrm{mL}$, respectively, but without significant differences between the groups $(p=0.672)$.

Conclusion Maternal serum vitamin $D$ levels did not present significant differences among pregnant women with AGA, SGA, or FGR fetuses between 26 and 36 weeks of gestation according to EFW. received

January 21,2020

accepted

July 21,2021
DOI https://doi.org/ 10.1055/s-0041-1735158. ISSN 0100-7203. (c) 2021. Federação Brasileira de Ginecologia e Obstetrícia. All rights reserved.

This is an open access article published by Thieme under the terms of the Creative Commons Attribution License, permitting unrestricted use, distribution, and reproduction so long as the original work is properly cited. (https://creativecommons.org/licenses/by/4.0/)

Thieme Revinter Publicações Ltda., Rua do Matoso 170, Rio de Janeiro, RJ, CEP 20270-135, Brazil 


\section{Resumo}

Palavras-chave
- gestação
- concentração sérica
materna
- vitamina D
- pequeno para idade
gestacional
- restrição de
crescimento fetal

Objetivo Avaliar o nível sérico materno de vitamina $\mathrm{D}$ em fetos adequados para idade gestacional (AIG), pequenos para idade gestacional (PIG) e com restrição de crescimento (RCF) de acordo com a estimativa de peso fetal (EPF).

Métodos Realizou-se um estudo transversal envolvendo 87 gestantes entre 26 e 36 semanas, sendo: 38 do grupo AIG, 24 do grupo PIG e 25 do grupo RCF. A dosagem sérica materna de vitamina $D$ foi realizada pelo método de quimiluminescência. Para as comparações entre os grupos, utilizou-se o teste exato de Fisher.

Resultados A média \pm desvio-padrão (DP) da idade materna (anos) e do índice de massa corporal $\left(\mathrm{kg} / \mathrm{m}^{2}\right)$ nos grupos AIG, PIG e RCF foram 25,26 $\pm 8,40$ / 26,57 $\pm 4,37$; $25,04 \pm 8,44 \mid 26,09 \pm 3,94$; e 25,48 $\pm 7,52$ / 26,24 $\pm 4,66$, respectivamente $(p>0,05)$. A concentração sérica materna de vitamina $D$ (médias \pm desvios-padrão) dos grupos AIG, PG e RCF foram $22,47 \pm 8,35 \mathrm{ng} / \mathrm{ml} ; 24,80 \pm 10,76 \mathrm{ng} / \mathrm{ml}$; e $23,61 \pm 9,98 \mathrm{ng} / \mathrm{ml}$, respectivamente, contudo, sem diferenças significativas entre os grupos $(p=0,672)$.

Conclusão A concentração sérica materna de vitamina $D$ não apresentou diferenças significantes entre gestantes com fetos AIG, PIG ou RCF entre 26 e 36 semanas de acordo com a EPF.

\section{Introduction}

Fetal growth restriction (FGR) affects $\sim 5$ to $10 \%$ of pregnancies and is the second obstetric complication with higher perinatal mortality, responsible for $\sim 30 \%$ of stillbirths, as well as a cause of higher frequency of premature births and intrapartum asphyxia. ${ }^{1}$ Small for gestational age (SGA) fetuses are those with prediction of weight below the $10^{\text {th }}$ percentile for gestational age, without impairing their genetic potential for growth. ${ }^{2}$

Currently, the classification of FGR follows the Delphi consensus, in which the fetuses are classified with early $(<$ 32 weeks) and late fetal growth restriction ( $\geq 32$ weeks), excluding congenital anomalies. ${ }^{3}$ Hypertrophy of fetal cells begins approximately at 32 weeks, and the importance given to the abdominal circumference (AC) is justified by the reduction of the liver, with reduction of glycogen storage associated with a decrease in abdominal fatty tissue. ${ }^{4}$

Vitamin D is a steroid involved in intestinal absorption and regulation of calcium homeostasis and is essential for the formation and maintenance of healthy and strong bones. Vitamin D deficiency may be due to inadequate exposure to the sun, inefficient food intake, decrease in absorption, and abnormal metabolism. ${ }^{5}$ Recent studies have related vitamin D deficiency during pregnancy to preeclampsia, ${ }^{6}$ gestational diabetes mellitus, ${ }^{7}$ and prematurity; ${ }^{8}$ yet, the relationship with FGR or SGA fetuses remains uncertain.

Bodnar et al. ${ }^{9}$ sought to elucidate the association between maternal serum concentrations of 25-hydroxyvitamin D (25 $(\mathrm{OH}) \mathrm{D})$ and the risk of SGA fetuses. They observed a relationship between maternal 25(OH)D serum level and risk of SGA in white women but not in black women, suggesting that vitamin $\mathrm{D}$ has a complex relationship with fetal growth that may vary according to race. Gernand et al. ${ }^{10}$ evaluated the association between maternal 25(OH)D levels and increased risk of placental insufficiency and observed a relationship between $25(\mathrm{OH}) \mathrm{D}$ and vascular damage, with $25(\mathrm{OH}) \mathrm{D} \geq$ $80 \mathrm{nmol} / \mathrm{L}$ associated with $49 \%$ lower risk of FGR in male newborns.

Therefore, the objective of the present study is to assess the vitamin D serum levels of mothers with SGA and FGR fetuses, comparing them with those of mothers with fetuses appropriate for gestational age (AGA) between 26 and 36 weeks of gestation according to estimated fetal weight (EFW).

\section{Methods}

A cross-sectional study was conducted between November 2016 and July 2019. The study was approved by the local research ethics committee under protocol No. 2.004.104, and all participants signed an informed consent form. The study was conducted at two university hospitals.

The inclusion criterion was pregnancy with a single fetus between 26 and 36 weeks of gestation, and the exclusion criteria were women in labor, fetuses with congenital anomalies detected on ultrasound, and chronic diseases such as hypertension, diabetes mellitus, autoimmune diseases, and heart diseases. Gestational age was determined by the date of the last menstrual period (LMP) and confirmed by ultrasonography performed up to 13 weeks.

The pregnant women were divided into 3 groups: 1) AGA (control); 2) SGA; and 3) FGR. Appropriate for gestational age was defined if the EFW was between $10^{\text {th }}$ and $90^{\text {th }}$ percentile according to the respective gestational age, ${ }^{11}$ following normal values of pulsatility index (PI) of the umbilical artery (UA), PI of the middle cerebral artery (MCA) and mean PI of the uterine artery (UtA). Fetuses were considered to have early-onset FGR when the gestational age was $<32$ weeks 
and the following criteria were present: EFW or $\mathrm{AC}<3^{\text {rd }}$ percentile for the gestational age or absent end-diastolic flow in the $\mathrm{UA}$; EFW or $\mathrm{AC}<10^{\text {th }}$ percentile for the gestational age, associated with a mean PI of the UtA or PI of the UA $>95^{\text {th }}$ percentile for the gestational age. ${ }^{3}$ Fetuses were considered to have late-onset FGR when the gestational age was $>32$ weeks and the following criteria were present: EFW or $\mathrm{AC}<3^{\text {rd }}$ percentile for the gestational age; EFW or $\mathrm{AC}<10^{\text {th }}$ percentile for the gestational age, associated with a mean PI of the UA $>95^{\text {th }}$ percentile for the gestational age, cerebroplacental ratio $(\mathrm{CPR})<5^{\text {th }}$ percentile for the gestational age, or AC/EFW ratio crossing centiles $>2$ quartiles on growth centiles. $^{3}$ Fetuses were considered SGA when EFW was between $3^{\text {rd }}$ and $10^{\text {th }}$ percentile and the criteria for earlyand late-onset FGR diagnosis were not met.

The ultrasound examinations were performed using a diagnostic WS80 Ultrasound System (Samsung Corp., Seoul, South Korea) by experienced examiners. Biometric measurements and EFW were determined, according to the equation by Hadlock et al. ${ }^{12}$ The Doppler parameters of the MCA and UA arteries were evaluated according to the curve of Arduini and Rizzo. ${ }^{13}$ These were considered altered when the $\mathrm{MCA} \mathrm{PI}<5^{\text {th }}$ percentile and/or the UA PI $>95^{\text {th }}$ percentile for gestational age. The UtA Doppler parameters were evaluated according to the curve reported by Gómez et al. ${ }^{14}$ and were considered abnormal when the mean $\mathrm{PI}>95^{\text {th }}$ percentile for gestational age. The volume of the amniotic fluid was evaluated by the four quadrants technique, according to the amniotic fluid index (AFI), ${ }^{15}$ with $\mathrm{AFI}<5 \mathrm{~cm}$ being considered oligohydramnios.

Maternal blood samples were collected during prenatal consultations only once and when the $\mathrm{EFW}<10^{\text {th }}$ percentile by ultrasound evaluation. Peripheral venous punctures were performed by two trained investigators, and the material was homogenized by inversion 5 to 8 times, accommodated in a sealed tube, and kept in a vertical position for 30 minutes. After complete blood coagulation, centrifugation was performed at 3,000 rpm for 15 minutes, and the samples were sent for laboratory analysis.

The ADVIA Centaur Vitamin D Total test (Siemens Healthineers, Erlangen, Germany) was used in the in vitro quantitative determination of total vitamin $\mathrm{D} 25(\mathrm{OH})$ in human serum and plasma. This is an 18-minute single pass competitive immunoassay using mouse monoclonal acridine ester (AE) labeled anti-vitamin D 25(OH) antibody and a fluorescein-labeled vitamin D analog. The ADVIA Centaur and ADVIA Centaur XP systems automatically perform the following steps: 1) dispenses $20 \mu \mathrm{L}$ of sample into a cuvette and incubates for 15 seconds; 2) dispenses $200 \mu \mathrm{L}$ auxiliary reagent and incubates for 4.5 minutes at $37^{\circ} \mathrm{C}$; 3 ) dispenses $50 \mu \mathrm{L}$ of lite reagent and incubates for 5.5 minutes at $37^{\circ} \mathrm{C}$; 4) dispenses $100 \mu \mathrm{L}$ of solid phase and $50 \mu \mathrm{L}$ of auxiliary container reagent and incubates for 2.75 minutes at $37^{\circ} \mathrm{C}$; 5 ) separates the solid phase from the mixture and aspirates unbound reagent; 6 ) washes the cuvette with wash solution 1 ; and 7) dispenses $300 \mu$ of acid reagent and base reagent to initiate the chemiluminescent reaction.

The ADVIA Centaur systems communicate the results by e-mail, which, according to an analysis of the literature, recommends the following classification for $25(\mathrm{OH}) \mathrm{D}$ levels: 1) deficiency $<20 \mathrm{ng} / \mathrm{mL}(50 \mathrm{nmol} / \mathrm{L}) ; 2)$ insufficiency between 20 and $30 \mathrm{ng} / \mathrm{mL}(50-75 \mathrm{nmol} / \mathrm{L}) ; 3)$ sufficiency between $\quad 30-100 \mathrm{ng} / \mathrm{mL} \quad(75-250 \mathrm{nmol} / \mathrm{L}) ;$ and 4) toxicity $>100 \mathrm{ng} / \mathrm{mL}(250 \mathrm{nmol} / \mathrm{L})$.

A power analysis was performed to calculate the sample size on the basis of the Cohen effect of 0.35 to achieve a power of $80 \%$ and an $\alpha$ of $5 \%$ to detect the differences in the evaluated parameters. ${ }^{16}$ Using the software $G 3.1$, the results suggested at least a sample size of 84 fetuses distributed homogeneously.

The data were transferred to an Excel 2010 spreadsheet (Microsoft Corp., Redmond, WA, USA) and analyzed with the SPSS for Windows, Version 15.0 (SPSS Inc., Chicago, IL, USA). The variables analyzed in the study were acquired on the day of the prenatal care consultation, when a questionnaire was applied with the following data: maternal age (years), weight $(\mathrm{Kg})$, height $(\mathrm{m})$, body mass index $(\mathrm{BMI})\left(\mathrm{m} / \mathrm{Kg}^{2}\right)$, gestational age (weeks), consumption of fish ( $150 \mathrm{~g}$ at least 3 times a week), sun exposure (at least 20 minute per day), sun protection (yeas or no), vitamin D replacement therapy (yes or no) and smoking (at least 1 cigarette per day). From the point of view of inferential statistics, to compare the groups (AGA, SGA, and FGR) with regard to the numerical variables of the study, we applied the analysis of variance model with a fixed factor and Tukey multiple comparisons method. For categorical variables, the Fisher exact test was used. In all analyses, a significance level of $p<0.05$ was set.

\section{Results}

Initially, blood samples from 100 pregnant women were collected; however, 13 samples were excluded due to the unavailability of the material at the time of analysis. Therefore, the final samples included 38 from the AGA group, 24 from the SGA group, and 25 in the FGR group. - Table 1 presents the descriptive analysis of maternal characteristics of the three groups.

Regarding categorical variables, the consumption of fish was low in all three groups. In relation to sunlight exposure, a more balanced result was observed, with $59.8 \%$ of pregnant women not sunbathing regularly. In relation to vitamin $\mathrm{D}$ and smoking, $94.3 \%$ and $86.2 \%$, respectively, did not supplement this vitamin and did not smoke. No pregnant woman reported using sunscreen. - Table 2 shows the comparison between the groups, with no statistical differences between them in any of the categorical variables.

The mean $( \pm S D$ ) levels of maternal serum vitamin $D$ for the AGA, SGA, and FGR groups $(22.47 \pm 8.35 \mathrm{ng} / \mathrm{mL}$, $24.80 \pm 10.76 \mathrm{ng} / \mathrm{mL}$, and $23.61 \pm 9.98 \mathrm{ng} / \mathrm{mL}$, respectively) showed no significant differences between the groups $(p=0.672)$ (-Table 2$)$. The results were compatible with vitamin D insufficiency (20-30 ng/mL) in the 3 groups.

Considering all cases included in the study, there was no significant correlation between vitamin $\mathrm{D}$ levels and gestational age $(r=-0.01, p=0.891)$ (-Fig. 1). Furtheremore, there was no significant correlation between vitamin $D$ levels and $\operatorname{EFW}(\mathrm{r}=-0.06, p=0.551)$ (-Fig. 2). 
Table 1 Comparison of numerical maternal variables in all three groups evaluated

\begin{tabular}{|c|c|c|c|c|c|c|c|c|c|c|c|c|c|}
\hline & \multicolumn{4}{|c|}{$\operatorname{AGA}(n=38)$} & \multicolumn{4}{|c|}{$\operatorname{SGA}(n=24)$} & \multicolumn{4}{|c|}{ FGR $(n=25)$} & \multirow[t]{2}{*}{$p$-value* } \\
\hline & Mean & SD & Min & Max & Mean & SD & Min & Max & Mean & SD & Min & Max & \\
\hline Age (years) & 25.3 & 8.4 & 15.0 & 42.0 & 25.0 & 8.4 & 15.0 & 41.0 & 25.5 & 7.5 & 15.0 & 42.0 & 0.983 \\
\hline GA (weeks) & 31.1 & 2.9 & 26.0 & 35.9 & 33.0 & 2.6 & 27.7 & 36.7 & 32.2 & 3.2 & 26.3 & 36.0 & 0.556 \\
\hline Maternal weight $(\mathrm{Kg})$ & 69.4 & 14.6 & 49.3 & 105.8 & 65.3 & 11.0 & 51.0 & 84.6 & 65.2 & 13.1 & 39.0 & 85.2 & 0.659 \\
\hline Maternal height (m) & 1.6 & 0.1 & 1.5 & 1.8 & 1.6 & 0.1 & 1.5 & 1.8 & 1.6 & 0.1 & 1.5 & 1.7 & 0.690 \\
\hline Maternal BMI $\left(\mathrm{Kg} / \mathrm{m}^{2}\right)$ & 26.6 & 4.4 & 19.8 & 37.1 & 26.1 & 3.9 & 20.7 & 35.2 & 26.2 & 4.7 & 16.4 & 34.6 & 0.922 \\
\hline EFW (grams) & 1725 & 526,6 & 958 & 2788 & 1678,0 & 408,7 & 879 & 2261,0 & 1409 & 455,4 & 630 & 2053 & 0.030 \\
\hline
\end{tabular}

Abbreviations: AGA, appropriate for gestational age; BMI, body mass index; EFW, estimated fetal weight; FGR, fetal growth restriction; GA, gestational age at blood sample collection; SD, standard deviation; SGA, small for gestational age.

*Tukey's multiple comparisons, $p<0.05$.

Table 2 Comparison of maternal variables and vitamin D level in the three analyzed groups

\begin{tabular}{lllll}
\hline & $\begin{array}{l}\text { AGA } \\
(\boldsymbol{n}=38)\end{array}$ & $\begin{array}{l}\text { SGA } \\
(\boldsymbol{n}=24)\end{array}$ & $\begin{array}{l}\text { FGR } \\
(\boldsymbol{n}=25)\end{array}$ & $p$-value \\
\hline $\begin{array}{l}\text { Fish } \\
\text { consumption }\end{array}$ & $7(18.4 \%)$ & $1(4.2 \%)$ & $5(20 \%)$ & $0.233^{*}$ \\
$\begin{array}{l}\text { Exposure to } \\
\text { sunlight }\end{array}$ & $15(39.5 \%)$ & $9(37.5 \%)$ & $11(44 \%)$ & $0.925^{*}$ \\
$\begin{array}{l}\text { Smoking } \\
\begin{array}{l}\text { Vitamin D } \\
\text { supplement }\end{array}\end{array}$ & $3(21.1 \%)$ & $2(8.3 \%)$ & $2(8 \%)$ & $0.325^{*}$ \\
$\begin{array}{l}\text { Vit D level } \\
\text { (ng/ml) }\end{array}$ & $22.5( \pm 8.3)$ & $1(4.2 \%)$ & $1(4 \%)$ & $0.999^{*}$ \\
\hline
\end{tabular}

Abbreviations: AGA, appropriate for gestational age; FGR, fetal growth restriction; SGA, small for gestational age, Vit, vitamin.

*Fisher exact test: frequency (centile).

${ }^{* *}$ ANOVA: mean (standard deviation), $p<0.05$.

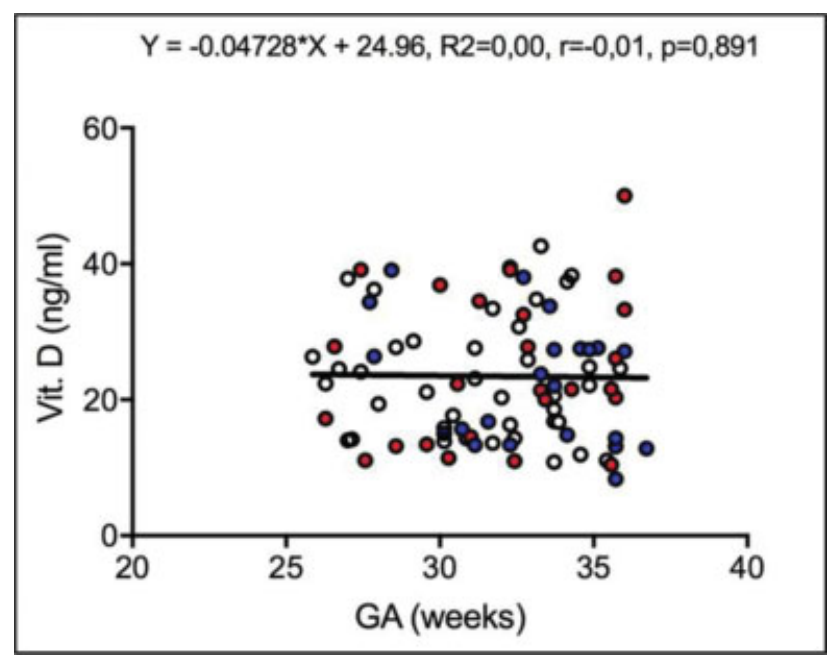

Fig. 1 Scatter plot of the vitamin D level $(\mathrm{ng} / \mathrm{ml})$ according to gestational age (weeks) in all pregnant women included in the study. Open dots: adequate for the gestational age; blue dots: small for the gestational age; red dots: fetal growth restriction. Pearson correlation coefficient, $p<0.05$.

\section{Discussion}

The inability of a fetus to attain the weight corresponding to its genetic potential increases morbidity and perinatal mortality; thus, FGR and obstetrical pathology must be diagnosed and managed early and adequately. ${ }^{17}$ Fetal growth restriction increases the risk of long-term sequelae, such as coronary heart disease, diabetes mellitus type 2 , arterial hypertension, and metabolic syndrome. ${ }^{18-20}$ Therefore, the knowledge of extrinsic predisposing factors could help in the early diagnosis of this pathology. Accordingly, we evaluated the effect of maternal parameters such as BMI on FGR, as a study found that pregnant women with FGR fetuses have low BMI compared with pregnant women with AGA fetuses. ${ }^{21}$

Classic obstetric complications have been associated with serum Vitamin D levels, ${ }^{22-25}$ even though the challenge of establishing a value specifically attributable to the pregnancy and puerperal period is recognized. However, the tendency of the available literature is to adopt indices from the non-pregnant population, which as can be seen in a recent systematic review with meta-analysis of 54

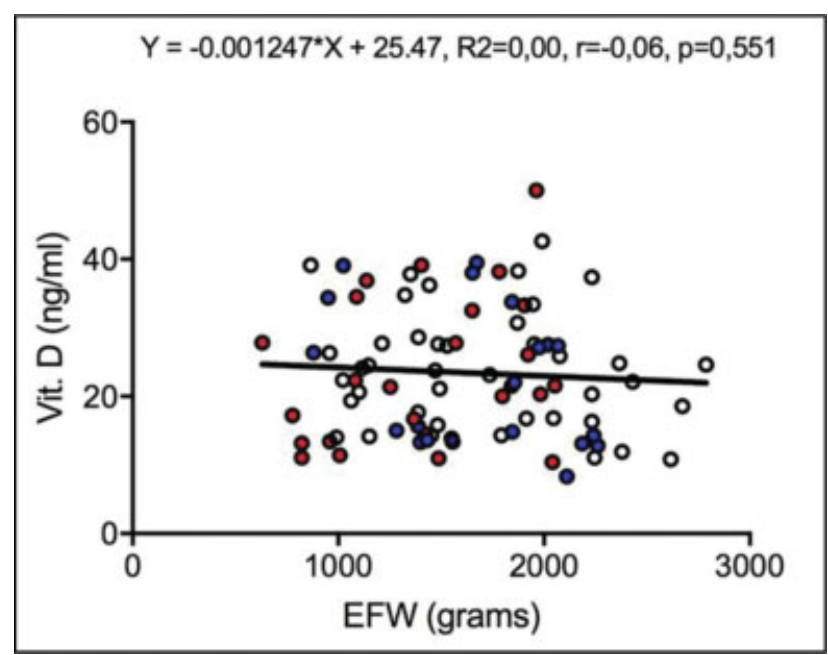

Fig. 2 Scatter plot of the vitamin D level $(\mathrm{ng} / \mathrm{ml})$ according to estimated fetal weight (grams) in all pregnant women included in the study. Open dots: adequate for the gestational age; blue dots: small for the gestational age; red dots: fetal growth restriction. Pearson correlation coefficient, $p<0.05$. 
articles. $^{26}$ Furthermore, we did not find any significant correlation between vitamin D level and gestational age, as well vitamin D level and EFW. This condition supported our choice for the Vitamin D scores that classified the group of women studied.

Vitamin D insufficiency is associated with obstetric pathologies such as preeclampsia and diabetes mellitus., During pregnancy, supplementation of this vitamin can be a viable strategy to prevent fetuses with low birth weight and $\mathrm{SGA} ; 22$ for this reason, the present study aimed at assessing the correlation of vitamin D with fetal growth.

Vitamin D deficiency in pregnant women is a major concern due to the risk of adverse obstetric pathologies and perinatal outcomes. ${ }^{23,24}$ The level of $25(\mathrm{OH}) \mathrm{D}$, which is the main form of vitamin D storage in humans, can, therefore, be measured in maternal blood to determine overall vitamin D status.

In the current study, low levels of vitamin $\mathrm{D}$ were observed in pregnant women between 26 and 36 weeks of gestation, living in a tropical country like Brazil, with abundant sunshine. In the south of China, which also has a tropical climate and where women were believed to have sufficient exposure to ultraviolet $B$ radiation and regular vitamin supplementation in prenatal care, a high prevalence of low levels of vitamin D between 16 and 20 weeks of gestation was also observed. ${ }^{25}$ No significant differences in adverse perinatal outcomes were observed between pregnant women with different vitamin D levels, except for a higher prevalence of gestational diabetes mellitus and preterm delivery in women with high serum vitamin D levels. $^{25}$

The present study demonstrated a high prevalence (75.9\%) of low serum vitamin D levels (deficient and insufficient levels) in pregnant women evaluated, regardless of the group assessed. A systematic review and meta-analysis, which included 54 eligible studies, reported that vitamin D deficiency $\left(<30 \mathrm{ng} / \mathrm{mL}\right.$ ) was associated with SGA, ${ }^{26}$ unlike our study, which did not identify this association. This systematic review also identified the occurrence of preterm birth and deficits in mental development and language when vitamin D insufficiency was present. ${ }^{26}$

In this study, five women received vitamin D supplementation, with three pregnant women having AGA fetuses, one having a SGA fetus, and the other one having a FGR fetus. In this study, we did not assess the differences associated with the skin color of pregnant women.

As limitations of the study are cross-sectional character, which did not evaluate the neonatal outcomes, thus making it impossible to compare with birthweight. Furthermore, although the sample size is within the statistical calculation, the small number of cases may have impacted our results. Futures studies with a higher number of cases are necessary to prove our results.

\section{Conclusion}

In summary, maternal serum concentration of vitamin D assessed between 26 and 36 weeks of pregnancy showed no significant differences between cases identified through EFW as AGA, SGA, or FGR.

Contributions

All authors participated in the conception and design of the present study; analysis and interpretation of data; draft or revision of the manuscript; and they have approved the manuscript as submitted. All authors are responsible for the reported research.

Conflict of Interests

The authors have no conflict of interests to declare.

\section{References}

1 Frøen JF, Gardosi JO, Thurmann A, Francis A, Stray-Pedersen B. Restricted fetal growth in sudden intrauterine unexplained death. Acta Obstet Gynecol Scand. 2004;83(09):801-807. Doi: 10.1111/ j.0001-6349.2004.00602.x

2 Barker ED, McAuliffe FM, Alderdice F, et al. The role of growth trajectories in classifying fetal growth restriction. Obstet Gynecol. 2013;122(2 Pt 1):248-254. Doi: 10.1097/AOG.0b013e31829ca9a7

3 Gordijn SJ, Beune IM, Thilaganathan B, et al. Consensus definition of fetal growth restriction: a Delphi procedure. Ultrasound Obstet Gynecol. 2016;48(03):333-339. Doi: 10.1002/uog.15884

4 Nardozza LMM, Zamarian ACP, Araujo Júnior E. New definition of fetal growth restriction: consensus regarding a major obstetric complication. Rev Bras Ginecol Obstet. 2017;39(07):315-316. Doi: 10.1055/s-0037-1603741

5 Pludowski P, Holick MF, Pilz S, et al. Vitamin D effects on musculoskeletal health, immunity, autoimmunity, cardiovascular disease, cancer, fertility, pregnancy, dementia and mortality-a review of recent evidence. Autoimmun Rev. 2013;12(10): 976-989. Doi: 10.1016/j.autrev.2013.02.004

6 Serrano NC, Guío E, Quintero-Lesmes DC, et al. Vitamin D deficiency and pre-eclampsia in Colombia: PREVitD study. Pregnancy Hypertens. 2018;14:240-244. Doi: 10.1016/j.preghy.2018.03.006

7 Hu L, Zhang Y, Wang X, et al. Maternal Vitamin D status and risk of gestational diabetes: a meta-analysis. Cell Physiol Biochem. 2018; 45(01):291-300. Doi: 10.1159/000486810

8 Kassai MS, Cafeo FR, Affonso-Kaufman FA, Suano-Souza FI, Sarni ROS. Vitamin D plasma concentrations in pregnant women and their preterm newborns. BMC Pregnancy Childbirth. 2018;18 (01):412. Doi: 10.1186/s12884-018-2045-1

9 Bodnar LM, Catov JM, Zmuda JM, et al. Maternal serum 25hydroxyvitamin D concentrations are associated with small-forgestational age births in white women. J Nutr. 2010;140(05): 999-1006. Doi: 10.3945/jn.109.119636

10 Gernand AD, Bodnar LM, Klebanoff MA, Parks WT, Simhan HN. Maternal serum 25-hydroxyvitamin D and placental vascular pathology in a multicenter US cohort. Am J Clin Nutr. 2013;98 (02):383-388. Doi: 10.3945/ajcn.112.055426

11 Hadlock FP, Harrist RB, Martinez-Poyer J. In utero analysis of fetal growth: a sonographic weight standard. Radiology. 1991;181 (01):129-133. Doi: 10.1148/radiology.181.1.1887021

12 Hadlock FP, Harrist RB, Sharman RS, Deter RL, Park SK. Estimation of fetal weight with the use of head, body, and femur measurements-a prospective study. Am J Obstet Gynecol. 1985;151(03): 333-337. Doi: 10.1016/0002-9378(85)90298-4

13 Arduini D, Rizzo G. Normal values of Pulsatility Index from fetal vessels: a cross-sectional study on 1556 healthy fetuses. J Perinat Med. 1990;18(03):165-172. Doi: 10.1515/jpme.1990.18.3.165

14 Gómez O, Figueras F, Fernández S, et al. Reference ranges for uterine artery mean pulsatility index at 11-41 weeks of gestation. Ultrasound Obstet Gynecol. 2008;32(02):128-132. Doi: 10.1002/ uog.5315 
15 Phelan JP, Smith CV, Broussard P, Small M. Amniotic fluid volume assessment with the four-quadrant technique at 36-42 weeks' gestation. J Reprod Med. 1987;32(07):540-542

16 Cohen J. Statistical power analysis for the behavioral sciences. New York: Routledge; 1988

17 Gourvas V, Dalpa E, Konstantinidou A, Vrachnis N, Spandidos DA, Sifakis S. Angiogenic factors in placentas from pregnancies complicated by fetal growth restriction (review). (review)Mol Med Rep. 2012;6(01):23-27. Doi: 10.3892/mmr.2012.898

18 Bamfo JE, Odibo AO. Diagnosis and management of fetal growth restriction. J Pregnancy. 2011;2011:640715. Doi: 10.1155/2011/ 640715

19 Harkness UF, Mari G. Diagnosis and management of intrauterine growth restriction. Clin Perinatol. 2004;31(04):743-764, vi. Doi: 10.1016/j.clp.2004.06.006

20 Ornoy A. Prenatal origin of obesity and their complications: Gestational diabetes, maternal overweight and the paradoxical effects of fetal growth restriction and macrosomia. Reprod Toxicol. 2011;32(02):205-212. Doi: 10.1016/j.reprotox.2011.05.002

21 Sawant LD, Venkat S. Comparative analysis of normal versus fetal growth restriction in pregnancy: the significance of maternal body mass index, nutritional status, anemia, and ultrasonography screening. Int J Reprod Med. 2013;2013:671954. Doi: $10.1155 / 2013 / 671954$

22 Tao RX, Meng DH, Li JJ, et al. Current recommended Vitamin D prenatal supplementation and fetal growth: results from the China-Anhui birth cohort study. J Clin Endocrinol Metab. 2018; 103(01):244-252. Doi: 10.1210/jc.2017-00850

23 Sahu M, Bhatia V, Aggarwal A, et al. Vitamin D deficiency in rural girls and pregnant women despite abundant sunshine in northern India. Clin Endocrinol (Oxf). 2009;70(05):680-684. Doi: 10.1111/j.1365-2265.2008.03360.x

24 Thandrayen K, Pettifor JM. Maternal vitamin D status: implications for the development of infantile nutritional rickets. Endocrinol Metab Clin North Am. 2010;39(02):303-320. Doi: 10.1016/ j.ecl.2010.02.006

25 Zhou J, Su L, Liu M, et al. Associations between 25-hydroxyvitamin D levels and pregnancy outcomes: a prospective observational study in southern China. Eur J Clin Nutr. 2014;68(08):925-930. Doi: $10.1038 /$ ejcn.2014.99

26 Tous M, Villalobos M, Iglesias L, Fernández-Barrés S, Arija V. Vitamin D status during pregnancy and offspring outcomes: a systematic review and meta-analysis of observational studies. Eur J Clin Nutr. 2020;74(01):36-53. Doi: 10.1038/s41430-018-0373-x 